\title{
Isolation, identification and characterization of soil bacteria for the production of ferulic acid through co-culture fermentation using banana stem waste
}

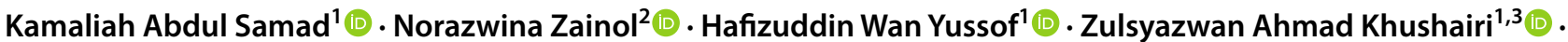 \\ Nurul Shareena Aqmar Mohd Sharif ${ }^{1}\left[\right.$. Nur Syahirah Mohd Syukri ${ }^{1}[$
}

Received: 14 November 2019 / Accepted: 31 January 2020 / Published online: 4 February 2020

(c) Springer Nature Switzerland AG 2020

\begin{abstract}
Exploitation of soil bacteria for production of ferulic acid (FA) is extensively performed since bacteria are the largest soil community that have the potential in producing degrading enzymes. This study aims to isolate, identify and characterize the most efficient soil bacteria for high FA yield via co-culture fermentation of banana stem waste (BSW). Bacteria were isolated and screened from acclimatized mixture of soil culture and BSW. ARB programme package and biolog system were employed for identification and characterization. The results reveal that four isolates closely related to Bacillus spp. and one Lysinibacillus sp. had greater potential to produce FA in very large amounts. Specifically, the maximum FA yield of $394.76 \mathrm{mg} / \mathrm{kg}$ was achieved using co-culture of Bacillus sp. MB2, Bacillus sp. WB8A and B. pumilus strain WB1 A, which was 2.5-fold higher than FA produced by single culture. The profiles of substrate utilization exposed strong hydrolyzation of pectin in those three potential cultures, while one showed strong hydrolyzation of glucuronic acid. The ability to efficiently hydrolyze the components proves that the chosen co-cultures are good sources of hydrolytic enzymes. The results suggest that the co-culture has contributed cooperative actions among the cultures to synergistically breakdown the FA linkage in BSW to produce high FA yield.
\end{abstract}

Keywords Co-culture $\cdot$ Banana stem waste $\cdot$ Ferulic acid $\cdot$ ARB software $\cdot$ Biolog system

\section{Introduction}

The possible use of ferulic acid (FA) as medicinal, food preservative and in several other potential applications has drawn considerable industrial and commercial interest towards this phenolic compound. Some of the notable industries that make use of this compound include pharmaceutical, food and cosmetic industries. FA is copiously present in the plant cell wall as covalent side chain components [1]. Different researchers have investigated various agriculture wastes such as sugar beet pulp, wheat bran, corncobs, paddy straw, switchgrass and triticale bran for their FA content. In this study, banana stem waste is used as substrate for FA production. Notably, banana stem contains about $15.42 \%$ lignin, $53.45 \%$ cellulose and $28.56 \%$ hemicellulose [2]. The use of this second largest cultivated tropical fruit, that generates several tons of underused byproduct and waste for ferulic acid production presents

Electronic supplementary material The online version of this article (https://doi.org/10.1007/s42452-020-2151-3) contains supplementary material, which is available to authorized users.

$\triangle$ Norazwina Zainol, azwina@ump.edu.my | ${ }^{1}$ Faculty of Chemical and Process Engineering Technology, Universiti Malaysia Pahang, Lebuhraya Tun Razak, 26300 Gambang, Kuantan, Pahang, Malaysia. ${ }^{2}$ College of Engineering, Universiti Malaysia Pahang, Lebuhraya Tun Razak, 26300 Gambang, Kuantan, Pahang, Malaysia. ${ }^{3}$ School of Foundation and Interdisciplinary Studies, DRB-HICOM University of Automotive Malaysia, DRB-HICOM Automotive Complex, Lot 1449, PT 2204, Peramu Jaya Industrial Area, 26607 Pekan, Pahang, Malaysia. 
immense benefits. More interestingly, it is abundantly found and cheap. FA is ether-linked to lignin, and esterlinked to arabinoxylan, xyloglucan and pectin which often makes its recovery from these natural sources very challenging $[1,3]$.

Different methods have been explored to produce FA from various types of lignocellulosic biomass such as mechanical extraction, chemical extraction and enzymatic hydrolysis [4-6]. Chemical and enzymatic hydrolysis are the most widely-used methods for FA production that have been reported. However, the use of chemical processes such as alkaline hydrolysis, has certain drawbacks that the method is considered unsafe and unacceptable in the food and medical industries compared to a more conventional enzymatic approach. Hence, enzymatic hydrolysis is preferred as an alternative for FA production. The use of purified enzyme and fermentation by microorganism are currently used to produce FA from biomass by breaking down the linkage. Feruloyl esterase or ferulic acid esterase (FAE) is known as the most important enzyme to cleave the feruloyl-polysaccharide. On the other hand, several enzymes have been observed to facilitate the production of FA $[7,8]$.

FAE acts synergistically with other hemicellulases such as xylanase to maximize the microbial degradation of plant cell wall [9]. This has been proven by Uraji et al. [10] in their finding where combinational enzymes have significantly enhanced FA production in rice bran, wheat bran and corncob. Notwithstanding, it is worthy to note that despite the reported beneficial use of co-enzymes simultaneously, the process might give different results with the utilization of different types of substrates. Therefore, co-culture fermentation is being considered as a useful method that could effectively support FA production from BSW, by simultaneous act of enzymes induced naturally by co-culture during fermentation.

Besides high growth rate and resistance to extreme condition, the ability to produce multi enzyme complexes indicates that bacteria have the potential to produce several hydrolytic enzymes for FA production [11]. Soil contains the highest number of microbial communities which actively takes part in releasing chemical nutrients from the decaying of organic matter processes in soil through enzymatic hydrolysis. Bartolomé et al. [12] and Sarangi and Sahoo [13] are among the researchers that have utilized bacteria in their research to produce FA from brewer's spent grain and wheat bran through fermentation. While, fermentation using mixture of unknown cultures on oil palm frond (OPF) and BSW have been explored by Khushairi et al. [14] and Mohd Sharif et al. [15]. However, the mixed culture fermentation technique may sometimes be followed by limitations to obtain higher FA production since biotransformation of FA into other phenolic compounds, such as vanillin and vanillic acid, may occur during fermentation $[16,17]$. Therefore, FA production through co-culture (combination of several known cultures) fermentation is recommended in the production of high FA yield. Wei et al. [18] has observed FA production in the range of $0.2-1.8 \mu \mathrm{g} / \mathrm{mL}$ on chopped wheat straw, corn stalk, rice straw, Chinese wildrye and medicago sativa using co-cultures of Piromyces and Methanobrevibacter ruminantium where wheat straw was identified as the most potential source of production. While, Razak et al. [19] found that FA production from rice bran was four times greater than Aspergillus oryzae through fermentation of $A$. oryzae and Rhizopus oryzae co-culture. Therefore, the selection of the most useful microbe to produce co-culture may offer many advantages in the production of FA. Specifically, the synergistic action would help to release FA from plant cell wall more efficiently, thereby minimizing the risk of possible conversion into other products. Till this moment, there has not been a report on isolation of soil bacteria for co-culture fermentation to improve FA production from BSW. This makes it necessary to investigate some other bacterial strains which have ability to release ferulic acid effectively through co-culture fermentation. Co-culture therefore promotes the production of lignocellulolytic mixtures or complexes that improve the efficiency of biodegradation. Significant polysaccharide hydrolase production during fermentation will degrade various lignocellulose substrates with the ability to release FA from lignocellulosic biomass [18].

Therefore, this study was performed to isolate, identify and characterize an isolated co-culture from soil that has potential as FA producer using BSW as their sole carbon source. Isolates were obtained from acclimatized soil bacteria and their performances were evaluated for FA production via single and co-culture fermentation. Identification of the most efficient bacteria was achieved through $16 \mathrm{~S}$ rRNA gene sequencing. In addition, phylogenetic analysis was performed by ARB software package and calculated by Bayesian analysis to obtain a phylogenetic tree. The ARB software used in this study provides a comprehensive interaction tool to analyze ribosomal RNA data including import and export data in different format. In addition, the use of Bayesian analysis could provide a satisfactory and reliable phylogenetic at statistical consistency.

\section{Materials and methods}

\subsection{Raw material}

Collection of banana stem waste (BSW) from banana plantation near Kuantan, Pahang was done once the banana was harvested. The stem was cleaned to eliminate any 
dirt attached and the damaged stem layer was discarded before using as substrate. The stem was then sliced into $1 \mathrm{~cm}$ cube size and blended with distilled water at ratio of 1:1 $(\mathrm{g} / \mathrm{mL})$ using a Panasonic blender. The BSW slurry mixture was sterelized in an autoclave (Hirayama HVE-50, Japan) at $121{ }^{\circ} \mathrm{C}$ for $15 \mathrm{~min}$ to kill undesired microorganisms.

\subsection{Acclimatization and isolation of soil microbe}

Soil sample was also collected from a depth of about $5-10 \mathrm{~cm}$ below ground surface at banana plantation in Kuantan, Pahang. Acclimatization of soil microbe in BSW was prepared in triplicate by mixing a part of soil containing mixture of microorganism, with four parts of substrate containing BSW and distilled water into $5 \mathrm{~L}$-container. The containers were closed with cotton plug to avoid environmental contamination. The mixtures were incubated for a month at ambient temperature prior to isolation.

After a month, $1 \mathrm{~mL}$ of acclimatized soil microbe was pipetted out and suspended in $9 \mathrm{~mL}$ of $0.85 \%(\mathrm{w} / \mathrm{v}) \mathrm{NaCl}$ buffer (Merck KGaA, Germany). The mixture was shaken vigorously using mechanical vortex. One milliliter of the first dilution was added to the next $9 \mathrm{~mL}$ of $\mathrm{NaCl}$ buffer to create a serial dilution up to $10^{-6}$. Then, $100 \mu \mathrm{L}$ of each dilution was spread evenly on a petri dish containing nutrient agar (Merck KGaA, Germany) and incubated in an incubator (Memmert, USA) at $37^{\circ} \mathrm{C}$ for $24 \mathrm{~h}$. Pure colonies observed was further cultured in a parallel agar plate to ensure the purity of each colony. Pure colonies were kept at $4{ }^{\circ} \mathrm{C}$ for further use.

\subsection{Preparation of inoculum}

Pure culture inoculum was prepared for the use in screening of five potential strains with maximum production of FA from 46 isolates. Inoculum was prepared from a fresh bacterial colony. Quadrant streaking method was performed to obtain the colony. Streaked plate was incubated in an incubator for $24 \mathrm{~h}$ at $37^{\circ} \mathrm{C}$. Each pure colony of the 46 strains was scraped and inoculated into a different $28 \mathrm{~mL}-$ Universal bottle containing $10 \mathrm{~mL}$ of nutrient broth. For use in preliminary studies involving single culture fermentation, inoculum was then incubated at $37^{\circ} \mathrm{C}$ for $24 \mathrm{~h}$.

Similar steps were followed in order to prepare co-culture inoculum as prepared in the preliminary study. However, the pure culture inoculum of potential strains were incubated at $22 \mathrm{~h}$ instead on the basis of our results in previous work on the bacterial growth profile to obtain high density cell culture [20]. Further stage was accomplished by combining several combinations of the selected potential soil bacteria which showed high production of FA into a new $28 \mathrm{~mL}$-Universal bottles. The number of possible combinations can be calculated as in Eq. 1 [21].

$C(n, r)=\frac{n !}{r !(n-r) !}$

where $n$ represents the total number of strains, and $r$ represents the number of strains being chosen in a group. From the calculation, the number of possible combinations of two, three, four or five strains generated are 10, 10, 5 and 1 types of co-culture without considering the order of the strain and without any repetition. In this study, a combination generator tool (https://www.statisticshowto.datas ciencecentral.com/calculators/permutation-calculator -and-combination-calculator/) was used to obtain the possible combination cultures. A total of 26 types of co-culture could be developed from five selected strains which then being used for co-culture inoculum preparation. Identical volume of each pure culture was equally distributed with a total of $10 \%$ into another $100 \mathrm{~mL}$-Erlenmeyer flask containing $50 \mathrm{~mL}$ fresh nutrient broth. Co-culture inoculum was further incubated for $22 \mathrm{~h}$ at $37^{\circ} \mathrm{C}$ before use.

\subsection{Selection of the most potent co-culture}

The most potent co-culture was established through their achievement in the production of high amounts of FA. Prior to co-culture fermentation, a preliminary study was performed to determine the effectiveness of each isolate in the production of FA using single culture fermentation. The study was conducted by submerged fermentation using the BSW medium as its primary carbon source. The overnight pure culture inoculum previously prepared was used freshly for the fermentation process. Each of the inoculum culture was inoculated about $10 \mathrm{~mL}$ into $250-\mathrm{mL}$ Erlenmeyer flask, containing the BSW slurry substrate at ratio of $1: 1(\mathrm{~g} / \mathrm{mL})$. The working volume of the mixture was up to $100 \mathrm{~mL}$. The flask was closed using cotton plug and incubated for $24 \mathrm{~h}$ at $35^{\circ} \mathrm{C}$ and $150 \mathrm{rpm}$ using incubator shaker (Infors HT Ecotron, Switzerland) aseptically. Then the culture supernatant was collected after centrifugation process for $15 \mathrm{~min}$ at $5800 \mathrm{rpm}$ by refrigerated centrifuge (Eppendorf 5810R, Germany). The sample was analysed using high performance liquid chromatography (HPLC) to check the ferulic acid content. Co-culture fermentation was further conducted by inoculating $10 \%$ of co-culture inoculum instead, following same steps as the single culture fermentation method.

\subsection{Quantification of ferulic acid}

The FA content was determined using Agilent $1100 \mathrm{HPLC}$ equipment (USA) equipped with diod array detector (DAD) 
according to Chamkha et al. [22]. Chromatographic analysis was performed on Agilent Zorbaq SB-AQ C18 analytical column (USA) with an isocratic mobile phase made up of acetonitrile (Fisher Scientific, UK), Milli-Q ultrapure water (Millipore, USA) and acetic acid glacial (Fisher Scientific, UK) at a ratio of 30:69.5:0.5 (v/v). A $25 \mu \mathrm{L}$ injection volume at $0.6 \mathrm{~mL} / \mathrm{min}$ was set at wavelength of $280 \mathrm{~nm}$. Samples were filtered using $0.2 \mu \mathrm{m}$ nylon syringe filter prior to analyzing and the FA content was measured by comparing the result with the calibration curve of standard ferulic acid (99\%, Sigma Aldrich, USA).

\subsection{Biochemical test}

Biochemical test for the selected five bacterial strains from the preliminary study which showed best performance in releasing FA was performed using Biolog GEN III MicroPlate System by referring the OmniLog ID System User Guide instructed by the manufacturer (Biolog, Hayward, CA). A pure colony was picked using a sterile cotton swab and transferred into the inoculating fluid $B$ (IF-B). The IF-A was tilted gently upside-down to obtain a uniform suspension. Then, the target cell density was obtained at range $93-98 \%$ by using a turbidimeter. About $100 \mu \mathrm{L}$ of cell suspension was inoculated into 96-well of the GEN III Microplate which consist of 71 types of carbon source and 23 chemical sensitivity assay tests using a multichannel micropipette. The mixture plate was then incubated at $37^{\circ} \mathrm{C}$ into Omnilog Unit for $24 \mathrm{~h}$. The result was interpreted by an identification system's software (Biolog, Hayward, CA).

\subsection{Identification by 16 S rRNA gene sequencing}

Genomic DNA was extracted from exponentially grown culture by using a GF-1 Bacterial DNA extraction kit (Vivantis Technologies, USA). Those five selected strains based on the preliminary study which showed higher contribution towards FA production were grown on nutrient agar plate overnight at $37^{\circ} \mathrm{C}$ to obtain pure culture colonies. Each type of bacteria was suspended in sterile distilled water and centrifuged at 12,138 rpm for $10 \mathrm{~min}$ in a microcentrifuge (Heraeus Instrument, Germany). The cell pellet was re-suspended to wash the cell and re-centrifuged twice prior to DNA extraction according to the manufacturer's instructions (Vivantis Technologist, USA). DNA purity was checked using Eppendorf BioPhotometer Plus (Eppendorf AG, Germany) with absorbance at A230, A260, A280 and $A 340$. The sample and $1 \mathrm{~kb}$ ladder were examined through gel electrophoresis at $70 \mathrm{~V}$ for $30 \mathrm{~min}$ on $1 \%$ agarose gel in a sub-cell GT agarose gel electrophoresis system (Bio-Rad Laboratories, USA) [23].
PCR was performed using bacterial ID kit according to the manufacturer's instruction (Profound Kestral Laboratories, Malaysia). Amplification of PCR product was performed using the primer 1492R (5'-TACGGYTACCTTGTT ACGACTT-3') and primer 27F (5'-AGAGTTTGATCMTGGCTC AG-3') (First Base Laboratories, Malaysia). The PCR conditions used for initial denaturation were $95^{\circ} \mathrm{C}$ for $4 \mathrm{~min}$, followed by $30 \mathrm{~s}$ denaturation cycles at $95^{\circ} \mathrm{C}$, an annealing at $57.5^{\circ} \mathrm{C}$ for $25 \mathrm{~s}$, an initial chain extension at $72^{\circ} \mathrm{C}$ for $1 \mathrm{~min}$, and a final extension at $72^{\circ} \mathrm{C}$ for $7 \mathrm{~min}$. PCR products were loaded into the well of $1 \%$ agarose gel with the control and ladder in Sub-Cell GT agarose gel electrophoresis system (Bio-Rad Laboratories, USA). Gel electrophoresis was run at $90 \mathrm{~V}$ for $1 \mathrm{~h} 50 \mathrm{~min}$ [23]. The agarose gel then was visualized with an UV transilluminator using Bio-imaging machine (Alpha Innotech, Germany) after stained. The gel was cut and purified for sequencing. The PCR products were sequenced at First Base Laboratories (Selangor, Malaysia). Briefly, the nearest neighbor of each isolate was searched and compared from the National Centre for Biotechnology Information (NCBI) database, using the Basic Local Alignment Search Tool (BLAST) (http://www. ncbi.nlm.nih.gov/blast/). All the sequences were deposited to NCBI GenBank with accession numbers between MH443316-MH443320.

\subsection{Sequence processing and analysis of phylogeny}

All the gene sequences of isolates and the nearest neighbor were analyzed using ARB software package to generate phylogenetic tree. The sequences were aligned using SILVA online SINA alignment to get the compatible sequence prior to being imported. They were then analyzed using an ARB 6.0.6 software [24, 25]. Bayesian phylogenetic tree was constructed through several steps. All the sequences were subjected to removal of ambiguous sequences using Gblocks [26]. Bayesian analysis was performed using MrBayes v3.0b4. Markov chains were run for 10,000,000 generations with sampling frequency of 100. The calculated tree obtained was imported into the $\mathrm{ARB}$, and the tree was constructed via an ARB parsimony method without changing the tree topology.

\section{Results and discussion}

\subsection{Isolation and selection of ferulic acid-producing strains}

The purpose of isolation in this study was to evaluate and identify the performance of various bacteria with the highest capacity to produce FA from BSW through submerged fermentation. FA is one of the most common 
phenolic compound that can be produced in high amounts in fermented product which is synthesized by microorganisms during fermentation [27]. This early stage of this research has to do with acclimatization of soil microbe for adaptation to utilize BSW as their sole carbon source prior to isolation. Acclimatization is a process where continuous exposure of a microbial population to a substrate results in a more rapid biodegradation of a compound to which it is exposed than initially observed [28, 29]. Use of acclimatized microbe to substrates before performing a research is believed to be a way of improving its ability to achieve high performance compared to other microbes that were not acclimatized to such environment [30]. In this study, 46 acclimatized soil microbes were successfully isolated from the BSW mixture after a month of acclimatization. The result suggested that the obtained bacteria might make effective use of BSW to survive and tolerate the provided environment. The ability of these bacteria utilize BSW effectively might be explained by mutation in one or more genes caused by change of the environmental condition exposed to allow the cell to degrade provided substrate $[29,31]$.
A number of research studies have used acclimated organism in obtaining adapted strains with improved biodegradable characteristic to enhance productivity [31-36]. A study conducted by Mate and Pathade [37] found that isolated microbes which earlier subjected to acclimatization with azo dye were usefully treated wastewater containing reactive dyes without giving toxicity of the biodegradation product. Similarly, Saha et al. [38] discovered a promising strategy using a microbiome acclimatized to lipidic-waste such as fat, oil, and grease (FOG) to improve hydrogen production and simultaneous production of C4-C7 fatty acids through hydrogenogenic acidogenic fermentation. Both studies showed similarities to this study which productivity have improved using acclimatized microbes with high tolerant and great degradation capabilities on the specified substrate compared to the unacclimated one.

The efficiency of each isolated bacterium to produce FA from BSW was further evaluated for $24 \mathrm{~h}$ fermentation. The result of preliminary study on FA production via single culture fermentation is presented in Fig. 1a. Among the 46 bacteria, only 37 were observed to be significant in producing FA. From the observation, six bacteria were
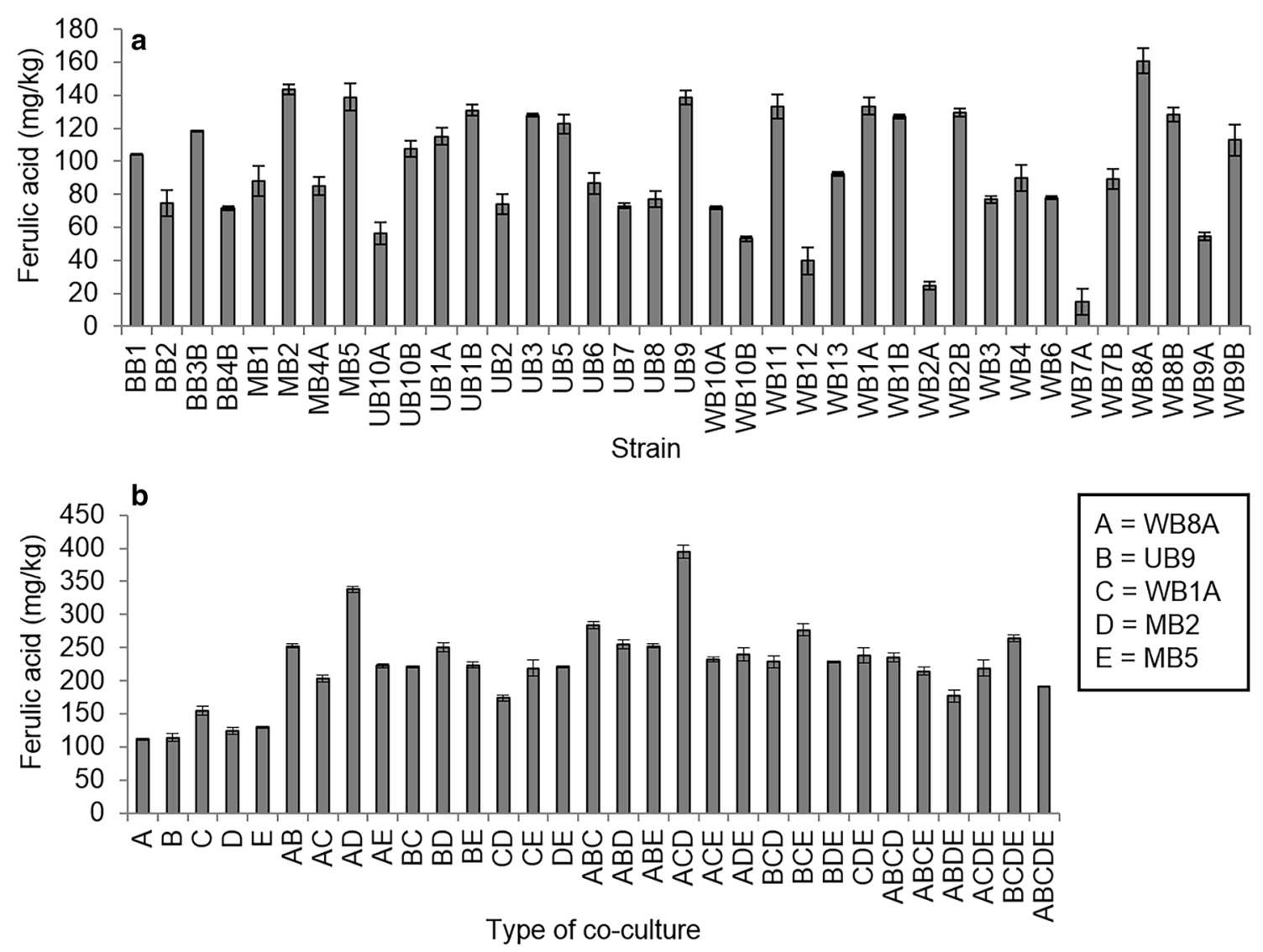

Fig. 1 Production of ferulic acid released by a single culture and $\mathbf{b}$ co-culture. Fermentation was performed under the same conditions for $24 \mathrm{~h}$ 
unable to show the presence of FA. A possible explanation to this might be due to insignificant amount of FA produced during the fermentation, or perhaps the bacteria was not capable to express an appropriate enzyme to hydrolyze feruloylated polysaccharide to release FA from BSW. Strain WB8A was observed to be the highest FA producer with a total production of about $160.78 \mathrm{mg} / \mathrm{kg}$. On the other hand, strain WB7A was found to produce the lowest amount of FA producer with a total production of about $14.81 \mathrm{mg} / \mathrm{kg}$. These values present a significant difference between the highest and the lowest FA producer. Specifically, the quantity of FA produced by WB8A is 10.86fold higher than WB7A. Strain MB2 was the second highest producer of FA followed by MB5, UB9 and WB1A with range values between 133.53 and $143.81 \mathrm{mg} / \mathrm{kg}$. From the result, the FA production achieved in this study was found to be lower than previously reported by Sarangi and Sahoo [13] where as much as $275 \mathrm{mg} / \mathrm{kg}$ of FA was recorded after 7 days fermentation with wheat bran using Staphylococcus aureus. However, at $24 \mathrm{~h}$ incubation, only $48 \mathrm{mg} / \mathrm{kg}$ of FA was observed in their study which showed that FA produced by strain WB8A in this study was 3.35 -fold higher and more efficient in utilizing BSW in shorter time.

Figure $1 \mathrm{~b}$ shows the FA production by 26 types of co-culture after $24 \mathrm{~h}$ fermentation. Notably, the result revealed significant improvement in FA production as shown by the co-cultures in comparison with single culture. Specifically, co-culture ACD presents an increase in FA production of up to about $394.76 \mathrm{mg} / \mathrm{kg}$ compared to just about $160.78 \mathrm{mg} / \mathrm{kg}$ of FA which was initially obtained through fermentation by WB8A (A) alone. On the other hand, the FA produced by $A D$ which is the second highest producer of $F A$ is about $338.08 \mathrm{mg} / \mathrm{kg}$. This is a difference of about $56.68 \mathrm{mg} / \mathrm{kg}$ when compared with the quantity produced by ACD. The presence of strain $C$ in ACD might be the reason for increasing of FA production. FA could be effectively released from lignocellulosic biomass due to the synergistic interaction between strains during fermentation. This significant difference in FA production indicates that co-cultures have better capability to increase FA production over the single culture. Co-culture could produce several polysaccharide hydrolases including FAE and xylanase with high biodegrading capabilities which useful for lignocellulosic bioconversion to FA [18]. This is well demonstrated in the study done by Wu et al. [39] which has recorded $70 \%$ of FA production from wheat bran under AnXyn11A (xylanase) and AnFaeA (feruloyl esterase) synergistic activity compared with $16.8 \%$ only produced by AnFaeA alone. Combination of both xylandegrading enzymes portrayed a great synergistic effect towards the production of high amount of FA. It is also encouraging to compare this result with that found by Valdez-Vazquez et al. [40] who also demonstrated that coculture of Clostridium cellulovorans and Clostridium acetobutylicum showed positive interaction by improving 2- to 3-fold productivity compared to single culture.

However, it was observed herein that the additions of strain may not always present good synergistic effect towards increased FA production. For example, combination of five strains $(A B C D E)$ was found to be the third lowest producer of FA followed by ABDE (second lowest) and $C D$ (lowest). Notably, a difference of about $203.90 \mathrm{mg} / \mathrm{kg}$ was observed between $A C D$ and $A B C D E$. This result suggest that poor synergistic effect of co-enzyme might occur due to inappropriate type of enzyme expressed by co-culture which might ineffectively degrade the substrate [39]. Therefore, it is important to ensure accurate combination through proper evaluation, in order to identify the most suitable combination to produce FA naturally.

Table 1 Characteristics of strain MB5, WB8A, MB2, UB9 and WB1A

\begin{tabular}{|c|c|c|c|c|c|}
\hline \multirow[t]{2}{*}{ Characteristic } & \multicolumn{5}{|l|}{ Strains } \\
\hline & MB5 & WB8A & MB2 & UB9 & WB1A \\
\hline Pigmentation & Light brown & White & White & Clear & Buff \\
\hline Optical property & Opaque & Opaque & Opaque & Transparent & Translucent \\
\hline Shape & Irregular & Circular & Circular & Irregular & Circular \\
\hline Surface & Smooth & Rough and shiny & Rough and dull & Smooth & Shining \\
\hline Elevation & Flat & Umbonate & Raised & Flat & Convex \\
\hline Margin & Entire & Irregular & Irregular & Entire & Entire \\
\hline
\end{tabular}




\subsection{Identification and characterization of ferulic acid-producing strains}

Bacterial morphologies of the five strains were observed in terms of their macroscopic as well as microscopic characteristics as roughly summarized in Table 1 . The results revealed that all the strains were confirmed as gram-positive and rod-shape bacterium. Gram-positive bacteria are often differentiated based on chemical and physical properties of the bacteria. Generally, they contain thicker peptidoglycan properties in their cell wall compared to gram negative bacteria and this protect and enables the grampositive bacteria to withstand extreme environments [41]. Previous studies have established that FAEs take a wide range of temperature and $\mathrm{pH}$ stabilities, with more than $60 \%$ of optimal activities between temperature of 25 and $50{ }^{\circ} \mathrm{C}$ and between pH 5.0 and $7.5[42,43]$. Nevertheless, there are also some of the FAEs that are categorized into four groups: $A, B, C$ and $D$ depending on their specificity of substrates, may have strong stability at extreme $\mathrm{pH}$ between 9.0 and 10.0 and temperature between 55 and $60{ }^{\circ} \mathrm{C}$ [44-47]. Gram-positive bacteria are known to have great potential as lignocellulose-degrading bacteria especially for lignin degradation which is important in this study to facilitate the production of desired phenolic compound from lignocellulosic waste [48].

Identification of selected bacteria through 16S rRNA sequence showed that the bacterial strains were classified as the genus of Bacillus spp. and Lysinibacillus sp. by comparing with BLAST result. The result reflects that of Donaghy et al. [49] who found a number of bacteria from Bacillus sp. possess the capabilities in producing FAE activity. On the other hand, Lysinibacillus sp. is the first genus that has been reported as having potential for FA production. A phylogenetic tree obtained clearly demonstrates the relatedness between the strains and nearest neighbor of each strain as portrayed in Fig. 2. The tree obviously demonstrated that WB8A, MB2 and UB9 could only be resolved to the genus. They were grouped in the same clade which is closely related to Bacillus cereus, Bacillus thuringiensis and Bacillus anthracis with a slight difference in term of sequence compared to the database. $B$. cereus and $B$. thuringiensis are genetically distinguishable. To date, the genetic relationships between $B$. cereus and $B$. thuringiensis have been comprehensively investigated. However, there are no sufficiently convincing results, and this makes it a bit difficult to classify both species. According to Peruca et al. [50] sometimes both species are classified together, whereas at other times $B$. thuringiensis is categorized as a subspecies of $B$. cereus which really makes the classification so complicated.

In contrast, strain WB1A and MB5 were $100 \%$ closely related to Bacillus pumilus and Lysinibacillus fusiformis, respectively. Bacillus spp. and related genera are the most attractive group of bacteria in industrial biotechnology due to its unique enzyme which shows resistance to high $\mathrm{pH}$ and temperature [51]. Therefore, it is advantageous to enhance FA production using these strains through coculture fermentation for natural production.
Fig. 2 Phylogenetic tree based on amplified $16 \mathrm{~S}$ rRNA gene sequence including nearest neighbor of known species. The scale bar for nucleotide sequence difference was recorded as 0.1. Fretibacterium fastidiosum is an outgroup

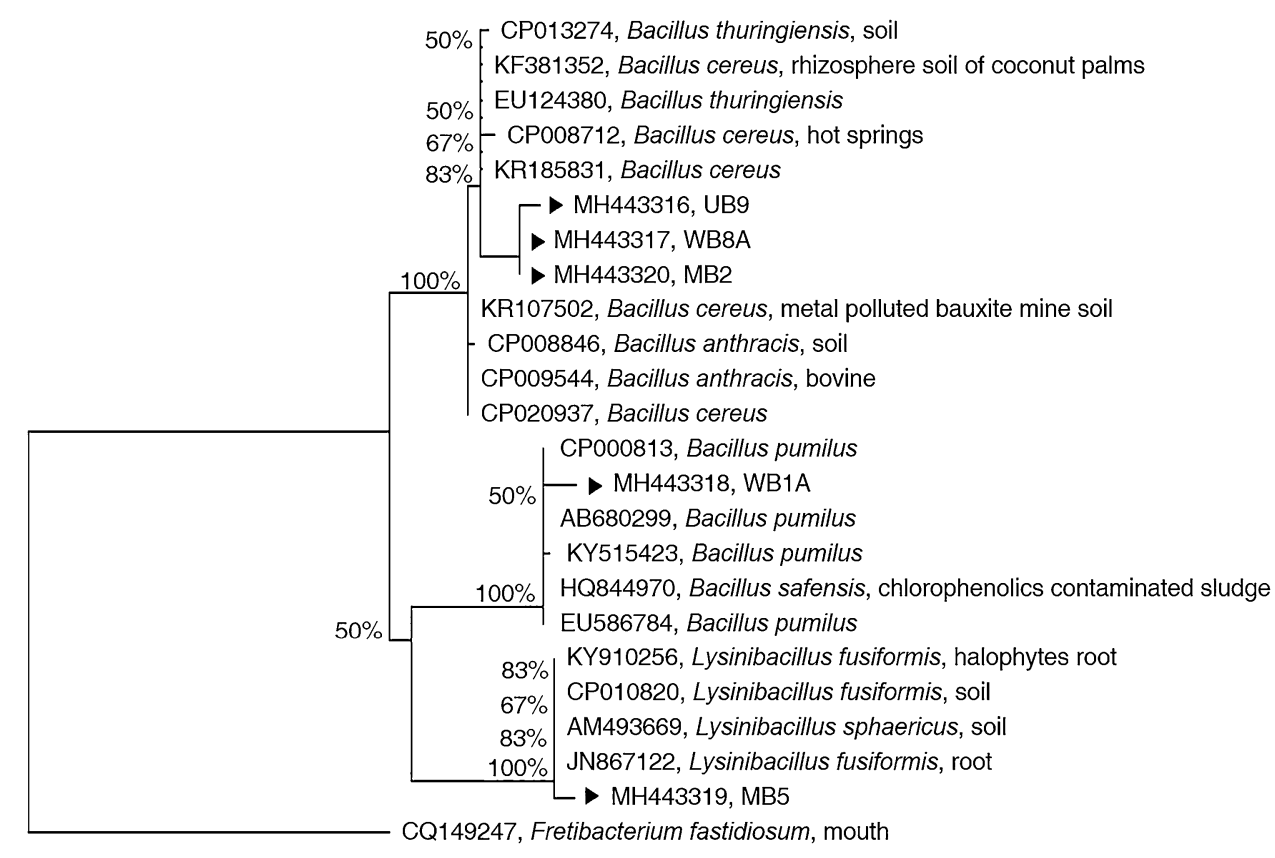




\subsection{Biochemical properties of the selected ferulic acid-producing strains}

Biolog Gen III Microplate system is beneficial to evaluate the characteristics of bacteria to react with different type of substrate within a short time. Positive results have been shown by many studies in estimating metabolic activities of microbe using the system [52-56]. Substrate utilization test using the system interprets the potential of bacteria to ferment and hydrolyze various substrates simultaneously at the same plate. Reaction for $24 \mathrm{~h}$ in this study was enough for each strain to be evaluated for carbon source utilization by strains or resistance to inhibit the chemicals. Species from the same family could react with the same carbon sources which may display similar substrate utilization profile. Performance of each strain in utilizing 71 types of substrate (column 1-9) and 23 types of chemical sensitivity (column 10-12) are shown in Fig. 3 and the details are described in Supplementary Table S1. From the figures, MB2 shows its ability in utilizing 44 types of substrates and sensitive to
15 types of chemicals which presented by purple well for strong hydrolyzation and half-filled blue for weak hydrolyzation. Meanwhile, MB5, WB1A, WB8A and UB9 are able to utilize $47,49,52$ and 62 types of substrate and sensitive to $15,15,20,16$ and 11 types of chemical, respectively.

The ability of bacteria to utilize several monomeric compounds reflects the ability of the microbes to degrade lignocellulosic biomass during fermentation. Selected substrate utilization from Fig. 3 that reveals hydrolytic activities on lignocellulosic biomass are summarized in Table 2 . The results of 11 types of substrate including D-cellobiose, a-D-glucose, D-mannose, D-fructose, D-galactose, D-fucose, L-fucose, L-rhamnose, pectin, D-galacturonic acid and D-glucuronic acid were selected for further evaluation since the profiles could represent hydrolytic activity of lignocellulosic biomass during fermentation process. Utilization of the components could demonstrate the potential of bacterial strains in breaking the ester and ether linkage that link hemicellulose and lignin to FA and other cellulose components to enhance the production of FA from
Fig. 3 Profile of different substrate utilization of a Bacillus sp. MB2 b Lysinibacillus fusiformis MB5 c Bacillus pumilus WB1 A d Bacillus sp. WB8A and e Bacillus sp. UB9. The purple, half-filled blue and blank color well indicate strong reaction, weak reaction and no reaction, respectively during incubation. $\mathrm{A} 1$ and $\mathrm{A} 10$ are positive and negative control well
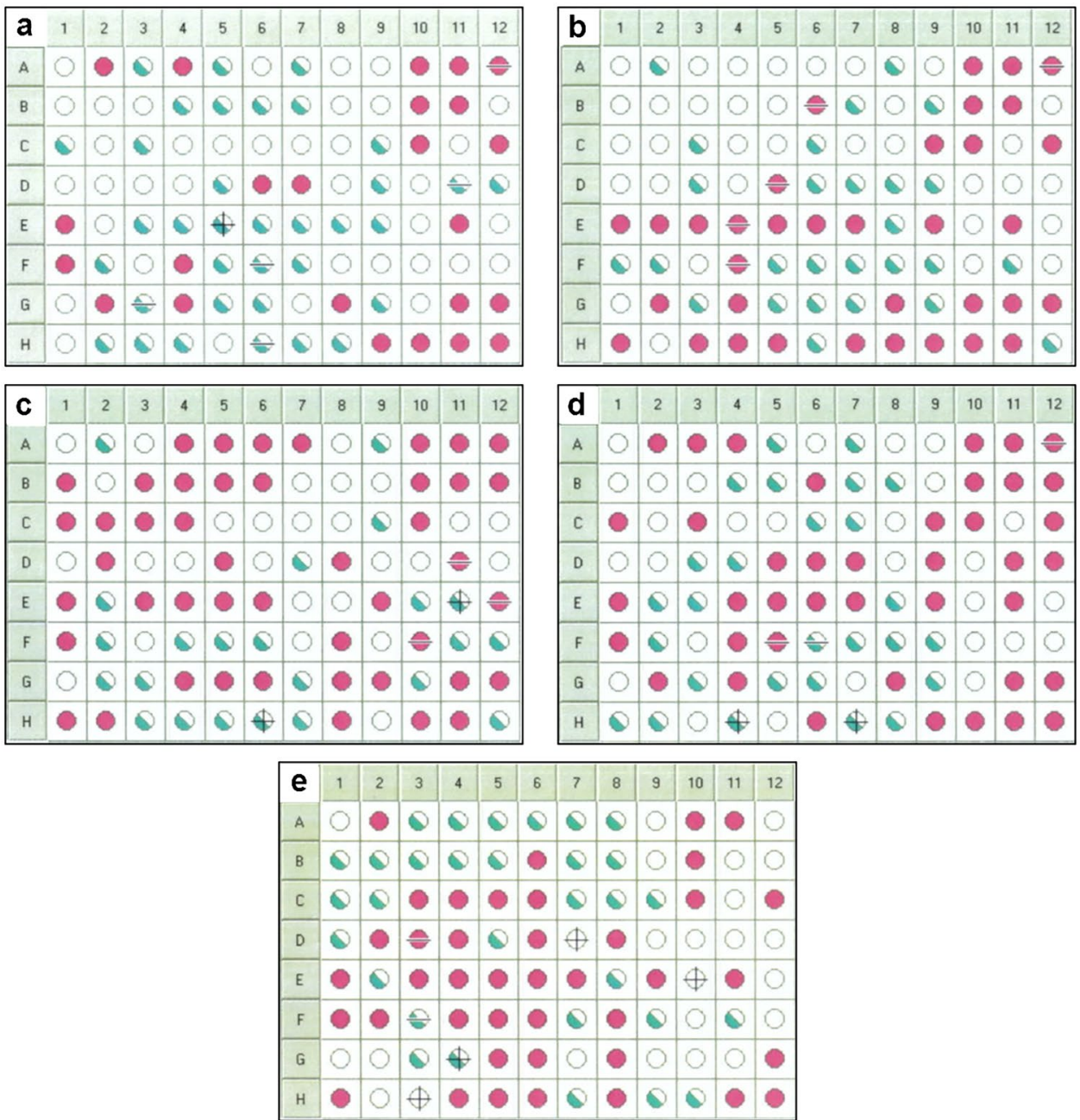
Table 2 Biochemical test for substrate utilization by different strains

\begin{tabular}{llllll}
\hline Type of carbon source & MB2 & WB8A & WB1A & MB5 & UB9 \\
\hline D-Cellobiose & W & W & + & - & W \\
a-D-Glucose & W & + & + & - & W \\
D-Mannose & - & - & + & - & W \\
D-Fructose & W & + & + & W & + \\
D-Galactose & - & - & + & - & + \\
D-Fucose & - & W & - & W & + \\
L-Fucose & - & W & - & - & W \\
L-Rhamnose & - & - & - & - & W \\
Pectin & + & + & + & W & + \\
D-Galacturonic acid & W & W & W & W & + \\
D-Glucuronic acid & W & + & W & W & + \\
\hline
\end{tabular}

Symbol of,$+ W$ and - represent the positive, weak, and negative reaction of strains on substrate, respectively

lignocellulosic biomass. Glucose is a basic unit of cellulose which cellobiose is the intermediate product [57]. The finding showed that all strains excluding strain MB5 may hydrolyze cellulose during fermentation since they could utilize both D-cellobiose and D-glucose. Although strain MB5 was unable to utilize the component, the finding however revealed that all the bacterial strains have capabilities to utilize D-fructose, pectin, D-galacturonic acid and D-glucuronic acid. Hydrolyzation of those substrates are important because hemicellulose is made up of different combination of monomeric hexose and pentose sugar including D-glucose, D-mannose and D-galactose and organic acid such as D-galacturonic acid and D-glucuronic [58]. FA residues and diferulic acid esterified to arabinofuranosyl residue of glucuronoarabinoxylan which consisted of arabinose and glucuronic acid that branched to core chain of xylan [59]. While, galacturonic acid is the main structure of pectin in primary cell wall which may also contain rhamnose, xylose, arabinose, and galactose $[60,61]$. Interestingly, all strains could also hydrolyze pectin with specifically strong hydrolyzation by strain MB2, WB8A, WB1A and UB9, and weak hydrolyzation by MB5. The hydrolyzation of pectin is an important step in fermentation of BSW to produce FA as product since FA is a side chain of pectin which could be completed by type $B$ feruloyl esterase [62]. These results corroborate the findings of Kühnel et al. [42] who reported $60 \%$ of FA production using type $B$ feruloyl esterase from sugar beet pectin oligomers as a substrate.

In this research, only five microbes were used to evaluate the biodegradable ability of the strains utilizing substrate utilization profile since the co-culture used in this study was developed from these strains. Substrate degradation profiles suggest that the presence of hydrolytic enzymes produced by bacterial strains could use the lignocellulosic biomass component as their carbon source. The results explain why higher FA production could be observed in these five strains from Bacillus spp. and Lysinibacillus $\mathrm{sp}$. as where the microbes could produce mixtures of enzymes to degrade lignocellulosic biomass during fermentation. Although these strains have potential as a good enzyme producer, the substrate utilization profile provided does not include lignin or lignin-related aromatic compounds as a substrate to clarify the activity of lignin degradation, which is the major limitation of this study to determine its effectiveness as lignin degraders. However, it is predicted that these strains could attack lignin structure parts to gain access to cellulose and hemicellulose rich in energy since BSW is the only carbon source provided for the fermentation [63]. Therefore, rationally, the probability of these strains producing lignin degrading enzymes is higher. Indeed, the findings of this study are aligned with other studies where it has been reported that Bacillus spp. and Lysinibacillus spp. could exhibit ligninolytic, cellulolytic and/or hemicellulolytic activities [64-66]. From the experimental point of view, more research is necessary to explore the ability of these strains as degrading bacteria to expand our understanding since several questions still remain to be answered.

\section{Conclusions}

The present study was performed to isolate the most promising soil co-culture for ferulic acid production through submerged fermentation. This study identified five out of thirty-seven strains as the highest FA producer which belongs to Bacillus spp. and Lysinibacillus sp. The study found that most of the strains could degrade $D$-cellobiose, a-D-glucose, D-mannose, D-fructose, D-galactose, D-fucose, L-fucose, L-rhamnose, pectin, D-galacturonic acid and D-glucuronic acid which proved their capabilities to manifest hydrolytic activities to produce FA effectively. From the investigation, co-culture of Bacillus sp. strain MB2, Bacillus sp. strain WB8A and B. pumilus strain WB1A was found to efficiently contribute $394.76 \mathrm{mg} / \mathrm{kg}$ of FA production from BSW in comparison with single culture (only $160.78 \mathrm{mg} / \mathrm{kg}$ of FA produced by Bacillus sp. strain WB8A). The findings suggest that co-culture fermentation may enhance FA production as a result of synergistic degrading activity. 
Acknowledgements We would like to thank Faculty of Chemical and Process Engineering Technology, University Malaysia Pahang for providing the facilities to accomplish the research. Our special thanks also go to Dr. Mohd Azrul Naim Mohamad and Nurul Syakira Zainuddin from International Islamic University Malaysia for their technical assistance. Dr. Kamaliah Abdul Samad is the recipient of University Malaysia Pahang Post-Doctoral Fellowship in this research.

\section{Compliance with ethical standards}

Conflict of interest The authors declare that they have no conflict of interest.

\section{References}

1. Kumar N, Pruthi V (2014) Potential applications of ferulic acid from natural sources. Biotechnol Reports 4:86-93. https://doi. org/10.1016/j.btre.2014.09.002

2. Silveira MLL, Furlan SA, Ninow JL (2008) Development of an alternative technology for the oyster mushroom production using liquid inoculum. Ciênc Tecnol Aliment 28:858-862. https ://doi.org/10.1590/S0101-20612008000400014

3. Wong DWS, Chan VJ, Batt SB, Sarath G, Liao H (2011) Engineering Saccharomyces cerevisiae to produce feruloyl esterase for the release of ferulic acid from switchgrass. J Ind Microbiol Biotechnol 38:1961-1967. https://doi.org/10.1007/s1029 5-011-0985-9

4. Salleh NHM, Daud MZM, Arbain D, Ahmad MS, Ismail KSK (2011) Optimization of alkaline hydrolysis of paddy straw for ferulic acid extraction. Ind Crops Prod 34:1635-1640. https:// doi.org/10.1016/j.indcrop.2011.06.010

5. Ismail SN, Zainol N (2014) Optimization of ferulic acid extraction from banana stem waste. Asian J Microbiol Biotechnol Environ Sci 16:479-484

6. Pérez-Rodríguez N, Torrado Agrasar A, Domínguez J (2017) High hydrostatic pressure as pretreatment and adjuvant for the enzymatic release of ferulic acid from corn cob. Process Biochem 58:204-210. https://doi.org/10.1016/J.PROCBIO.2017.04.011

7. Gopalan N, Rodríguez-Duran LV, Saucedo-Castaneda G, Madhavan Nampoothiri K (2015) Review on technological and scientific aspects of feruloyl esterases: a versatile enzyme for biorefining of biomass. Bioresour Technol 193:534-544. https ://doi.org/10.1016/j.biortech.2015.06.117

8. Wang G, Liu Z, Xu L, Zhang H, Yan Y (2015) Probing role of key residues in the divergent evolution of Yarrowia lipolytica lipase 2 and Aspergillus niger eruloyl esterase A. Microbiol Res 178:27-34. https://doi.org/10.1016/J.MICRES.2015.05.011

9. Long L, Zhao H, Ding D, Xu M, Ding S (2018) Heterologous expression of two Aspergillus niger feruloyl esterases in Trichoderma reesei for the production of ferulic acid from wheat bran. Bioprocess Biosyst Eng 41:593-601. https://doi. org/10.1007/s00449-018-1894-3

10. Uraji M, Kimura M, Inoue $Y$, Kawakami K, Kumagai Y, Harazono K, Hatanaka T (2013) Enzymatic production of ferulic acid from defatted rice bran by using a combination of bacterial enzymes. Appl Biochem Biotechnol 171:1085-1093. https:// doi.org/10.1007/s12010-013-0190-6

11. Balasubramanian N, Simões N (2014) Bacillus pumilus S124A carboxymethyl cellulase; a thermo stable enzyme with a wide substrate spectrum utility. Int J Biol Macromol 67:132-139. https://doi.org/10.1016/j.ijbiomac.2014.03.014

12. Bartolomé B, Gómez-Cordovés C, Sancho Al, Díez N, Ferreira P, Soliveri J, Copa-Patiño JL (2003) Growth and release of hydroxycinnamic acids from Brewer's spent grain by Streptomyces avermitilis CECT 3339. Enzyme Microb Technol 32:140144. https://doi.org/10.1016/S0141-0229(02)00277-6

13. Sarangi PK, Sahoo HP (2010) Ferulic acid production from wheat bran using Staphylococcus aureus. N Y Sci J 3:79-81

14. Khushairi ZA, Yussof HW, Rodzri NA, Abu Samah R, Zainol N (2016) A factorial analysis study on factors contribution to ferulic acid production from oil palm frond waste. J Teknol 78:147-152. https://doi.org/10.11113/jt.v78.7339

15. Mohd Sharif NSA, Thor ES, Zainol N, Jamaluddin MF (2017) Optimization of ferulic acid production from banana stem waste using central composite design. Environ Prog Sustain Energy 36:1217-1223. https://doi.org/10.1002/ep.12560

16. Ma X, Daugulis AJ (2014) Effect of bioconversion conditions on vanillin production by Amycolatopsis sp. ATCC 39116 through an analysis of competing by-product formation. Bioprocess Biosyst Eng 37:891-899. https://doi.org/10.1007/s0044 9-013-1060-x

17. Mishra S, Kullu M, Sachan A, Vidyarthi AS, Sachan SG (2016) Bioconversion of ferulic acid to vanillic acid by Paenibacillus lactis SAMS-2001. Ann Microbiol 66:875-882. https://doi.org/10.1007/ s13213-015-1175-1

18. Wei Y-Q, Yang H-J, Long R-J, Wang Z-Y, Cao B-B, Ren Q-C, Wu T-T (2017) Characterization of natural co-cultures of Piromyces with Methanobrevibacter ruminantium from yaks grazing on the Qinghai-Tibetan Plateau: a microbial consortium with high potential in plant biomass degradation. AMB Express 7:160. https://doi.org/10.1186/s13568-017-0459-1

19. Abd Razak DL, Abd Rashid NY, Jamaluddin A, Sharifudin SA, Abd Kahar A, Long K (2017) Cosmeceutical potentials and bioactive compounds of rice bran fermented with single and mix culture of Aspergillus oryzae and Rhizopus oryzae. J Saudi Soc Agric Sci 16:127-134. https://doi.org/10.1016/j.jssas.2015.04.001

20. Samad KA, Zainol N, Syahirah N, Syukri M, Mohd Syukri NS (2016) Development of soil co-culture system for ferulic acid production. ARPN J Eng Appl Sci 11:2253-2257

21. Brualdi RA (2010) Introductory combinatorics, 5th edn. Pearson/ Prentice Hall, Englewood Cliffs

22. Chamkha M, Patel BKCC, Garcia J-L, Labat M (2001) Isolation of Clostridium bifermentans from oil mill wastewaters converting cinnamic acid to 3-phenylpropionic acid and emendation of the species. Anaerobe 7:189-197. https://doi.org/10.1006/ anae.2001.0382

23. Syedametova E (2013) Production of pravastatin by filamentous fungi isolated from soil. Dissertation, Universiti Malaysia Pahang

24. Ludwig W, Strunk O, Westram R, Richter L, Meier H, Yadhukumar Buchner A, Lai T, Steppi S, Jobb G, Förster W, Brettske I, Gerber S, Ginhart AW, Gross O, Grumann S, Hermann S, Jost R, König A, Liss T, Lüssmann R, May M, Nonhoff B, Reichel B, Strehlow R, Stamatakis A, Stuckmann N, Vilbig A, Lenke M, Ludwig T, Bode A, Schleifer K-H (2004) ARB: a software environment for sequence data. Nucleic Acids Res 32:1363-1371. https://doi.org/10.1093/ nar/gkh293

25. Pruesse E, Quast C, Knittel K, Fuchs BM, Ludwig W, Peplies J, Glöckner FO (2007) SILVA: a comprehensive online resource for quality checked and aligned ribosomal RNA sequence data compatible with ARB. Nucleic Acids Res 35:7188-7196. https:// doi.org/10.1093/nar/gkm864

26. Castresana J (2000) Selection of conserved blocks from multiple alignments for their use in phylogenetic analysis. Mol Biol Evol 17:540-552. https://doi.org/10.1093/oxfordjournals.molbe v.a026334

27. Yoshizawa K, Komatsu S, Takahashi I, Otsuka K (1970) Phenolic compounds in the fermented products part I. Origin of ferulic acid in saké. Agric Biol Chem 34:170-180. https://doi. org/10.1080/00021369.1970.10859607 
28. Das S, Raj R, Mangwani N, Dash HR, Chakraborty J (2014) Heavy metals and hydrocarbons: adverse effects and mechanism of toxicity. In: Das S (ed) Microbial biodegradation and bioremediation. Elsevier Inc., Amsterdam, pp 24-54

29. Knapp JS, Bromley-Challoner KCA (2003) Recalcitrant organic compounds. In: Mara D, Horan N (eds) Handbook of water and wastewater microbiology. Elsevier Inc., Amsterdam, pp 559-595

30. Leroi AM, Bennett AF, Lenski RE (1994) Temperature acclimation and competitive fitness: an experimental test of the beneficial acclimation assumption. Proc Natl Acad Sci 91:1917-1921. https ://doi.org/10.1073/pnas.91.5.1917

31. Cisterna-Osorio P, Lavin AG, Sastre-Andres H (2015) Impact of previous acclimatization of biomass and alternative substrates in sunflower oil biodegradation. DYNA 82:56-61. https://doi. org/10.15446/dyna.v82n193.45667

32. Wang Q, Yang M, Song X, Tang S, Yu L (2019) Aerobic and anaerobic biodegradation of 1,2-dibromoethane by a microbial consortium under simulated groundwater conditions. Int J Environ Res Public Health 16:3775

33. Xing SC, Mi JD, Chen JY, Xiao L, Wu YB, Liang JB, Zhang LH, Di Liao X (2019) The metabolism and morphology mutation response of probiotic Bacillus coagulans for lead stress. Sci Total Environ. https://doi.org/10.1016/j.scitotenv.2019.07.296

34. Zou S, Yan N, Zhang C, Zhou Y, Wu X, Wang J, Liu Y, Zhang Y, Rittmann BE (2019) Acclimation of nitrifying biomass to phenol leads to persistent resistance to inhibition. Sci Total Environ. https://doi.org/10.1016/j.scitotenv.2019.133622

35. Nakasaki K, Koyama M, Maekawa T, Fujita J (2019) Changes in the microbial community during the acclimation process of anaerobic digestion for treatment of synthetic lipid-rich wastewater. J Biotechnol 306:32-37. https://doi.org/10.1016/j.jbiot ec.2019.09.003

36. Bonner MTL, Shoo LP, Brackin R, Schmidt S (2018) Relationship between microbial composition and substrate use efficiency in a tropical soil. Geoderma 315:96-103. https://doi.org/10.1016/j. geoderma.2017.11.026

37. Mate MS, Pathade G (2012) Biodegradation of C.I. reactive red 195 by Enterococcus faecalis strain YZ66. World J Microbiol Biotechnol 28:815-826. https://doi.org/10.1007/s1127 4-011-0874-4

38. Saha S, Jeon BH, Kurade MB, Chatterjee PK, Chang SW, Markkandan K, Salama ES, Govindwar SP, Roh HS (2019) Microbial acclimatization to lipidic-waste facilitates the efficacy of acidogenic fermentation. Chem Eng J 358:188-196. https://doi. org/10.1016/j.cej.2018.09.220

39. Wu H, Li H, Xue Y, Luo G, Gan L, Liu J, Mao L, Long M (2017) High efficiency co-production of ferulic acid and xylooligosaccharides from wheat bran by recombinant xylanase and feruloyl esterase. Biochem Eng J 120:41-48. https://doi.org/10.1016/J. BEJ.2017.01.001

40. Valdez-Vazquez I, Castillo-Rubio LG, Pérez-Rangel M, SepúlvedaGálvez A, Vargas A (2019) Enhanced hydrogen production from lignocellulosic substrates via bioaugmentation with Clostridium strains. Ind Crops Prod 137:105-111. https://doi.org/10.1016/j. indcrop.2019.05.023

41. Kim SJ, Chang J, Singh M (2015) Peptidoglycan architecture of Gram-positive bacteria by solid-state NMR. Biochim Biophys Acta Biomembr 1848:350-362. https://doi.org/10.1016/J.BBAME M.2014.05.031

42. Kühnel S, Pouvreau L, Appeldoorn MM, Hinz SWA, Schols HA, Gruppen H (2012) The ferulic acid esterases of Chrysosporium lucknowense $\mathrm{C} 1$ : purification, characterization and their potential application in biorefinery. Enzyme Microb Technol 50:77-85. https://doi.org/10.1016/j.enzmictec.2011.09.008
43. Ding ZT, Xu DM, Bai J, Li FH, Adesogan AT, Zhang P, Yuan XJ, Guo XS (2019) Characterization and identification of ferulic acid esterase-producing Lactobacillus species isolated from Elymus nutans silage and their application in ensiled alfalfa. J Appl Microbiol 127:985-995. https://doi.org/10.1111/jam.14374

44. Deng H, Jia P, Jiang J, Bai Y, Fan T-P, Zheng X, Cai Y (2019) Expression and characterisation of feruloyl esterases from Lactobacillus fermentum JN248 and release of ferulic acid from wheat bran. Int J Biol Macromol 138:272-277. https://doi.org/10.1016/j.ijbio mac.2019.07.086

45. Wang X, Bai Y, Cai Y, Zheng X (2017) Biochemical characteristics of three feruloyl esterases with a broad substrate spectrum from Bacillus amyloliquefaciens H47. Process Biochem 53:109-115. https://doi.org/10.1016/j.procbio.2016.12.012

46. Shin HD, Chen RR (2006) Production and characterization of a type B feruloyl esterase from Fusarium proliferatum NRRL 26517. Enzyme Microb Technol 38:478-485. https://doi.org/10.1016/j. enzmictec.2005.07.003

47. Fazary AE, Ju YH (2007) Feruloyl esterases as biotechnological tools: current and future perspectives. Acta Biochim Biophys Sin (Shanghai) 39:811-828. https://doi.org/10.111 1/j.1745-7270.2007.00348.x

48. Huang D-L, Zeng G-M, Feng C-L, Hu S, Lai C, Zhao M-H, Su F-F, Tang L, Liu H-L (2010) Changes of microbial population structure related to lignin degradation during lignocellulosic waste composting. Bioresour Technol 101:4062-4067. https://doi. org/10.1016/J.BIORTECH.2009.12.145

49. Donaghy J, Kelly PF, McKay AM (1998) Detection of ferulic acid esterase production by Bacillus spp. and Lactobacilli. Appl Microbiol Biotechnol 50:257-260. https://doi.org/10.1007/s0025 30051286

50. Peruca APS, Vilas-Bôas GT, Arantes O (2008) Genetic relationships between sympatric populations of Bacillus cereus and Bacillus thuringiensis, as revealed by rep-PCR genomic fingerprinting. Mem Inst Oswaldo Cruz 103:497-500. https://doi. org/10.1590/S0074-02762008000500016

51. Sharp RJ, Riley PW, White D (1992) Heterotrophic thermophilic Bacilli. In: Kristjansson JK (ed) Thermophilic bacteria, first. CRC Press, Boca Raton, pp 19-50

52. Kumar M, Männistö MK, van Elsas JD, Nissinen RM (2016) Plants impact structure and function of bacterial communities in Arctic soils. Plant Soil 399:319-332. https://doi.org/10.1007/s1110 4-015-2702-3

53. Narayanamurthy V, Sweetnam JM, Denner DR, Chen LW, Naureckas ET, Laxman B, White SR (2017) The metabolic footprint of the airway bacterial community in cystic fibrosis. Microbiome 5:67. https://doi.org/10.1186/s40168-017-0289-z

54. Huys $G$, Purohit P, Tan CH, Snauwaert C, De Vos P, Al Saffar H, Am I', Obaid A, Busse H-J, Seemann T, Albert MJ (2017) Sphingobacterium cellulitidis $\mathrm{sp}$. nov., isolated from clinical and environmental sources. Int J Syst Evolut Microbiol. https://doi.org/10.1099/ ijsem.0.001832

55. Khalifa AYZ, AIMalki M (2018) Polyphasic characterization of Delftia acidovorans ESM-1, a facultative methylotrophic bacterium isolated from rhizosphere of Eruca sativa. Saudi J. Biol, Sci

56. Schmidt T, Kock MM, Ehlers MM (2018) Identification and characterization of Staphylococcus devriesei isolates from bovine intramammary infections in KwaZulu-Natal, South Africa 06 Biological Sciences 0604 Genetics. BMC Vet Res 14:324. https:// doi.org/10.1186/s12917-018-1655-1

57. Bonnin E, Saulnier L, Brunel M, Marot C, Lesage-Meessen L, Asther M, Thibault J-F (2002) Release of ferulic acid from agroindustrial by-products by the cell wall-degrading enzymes produced by Aspergillus niger I-1472. Enzyme Microb Technol 31:1000-1005. https://doi.org/10.1016/S0141-0229(02)00236-3 
58. Thakur VK, Thakur MK (2015) Chemical functionalization of carbon nanomaterials: chemistry and applications, first. CRC Press, Boca Raton

59. de Oliveira DM, Finger-Teixeira A, Rodrigues Mota T, Salvador VH, Moreira-Vilar FC, Correa Molinari HB, Craig Mitchell RA, Marchiosi R, Ferrarese-Filho O, Dantas dos Santos W (2015) Ferulic acid: a key component in grass lignocellulose recalcitrance to hydrolysis. Plant Biotechnol J 13:1224-1232. https://doi.org/10.1111/ pbi.12292

60. Edwards MC, Doran-Peterson J (2012) Pectin-rich biomass as feedstock for fuel ethanol production. Appl Microbiol Biotechnol 95:565-575. https://doi.org/10.1007/s00253-012-4173-2

61. Mathews SL, Pawlak J, Grunden AM (2015) Bacterial biodegradation and bioconversion of industrial lignocellulosic streams. Appl Microbiol Biotechnol 99:2939-2954. https://doi. org/10.1007/s00253-015-6471-y

62. Bonnin E, Garnier C, Ralet M-C (2014) Pectin-modifying enzymes and pectin-derived materials: applications and impacts. Appl Microbiol Biotechnol 98:519-532. https://doi.org/10.1007/s0025 3-013-5388-6
63. Horwath W (2015) Carbon cycling. In: Paul EA (ed) Soil microbiology, ecology and biochemistry. Elsevier, Amsterdam, pp 339-382

64. Chantarasiri A, Boontanom P, Nuiplot NO (2017) Isolation and characterization of Lysinibacillus sphaericus BR2308 from coastal wetland in Thailand for the biodegradation of lignin. AACL Bioflux 10:200-209

65. Chaudhary N, Qazi JI, Irfan M (2017) Isolation and identification of cellulolytic and ethanologenic bacteria from soil. Iran J Sci Technol Trans A Sci 41:551-555. https://doi.org/10.1007/s4099 5-017-0282-1

66. Montella S, Ventorino V, Lombard V, Henrissat B, Pepe O, Faraco V (2017) Discovery of genes coding for carbohydrate-active enzyme by metagenomic analysis of lignocellulosic biomasses. Sci Rep 7:42623. https://doi.org/10.1038/srep42623

Publisher's Note Springer Nature remains neutral with regard to jurisdictional claims in published maps and institutional affiliations. 